\title{
Irregular perspective shifts and perspective persistence, discourse-oriented and theoretical approaches
}

\author{
Caroline Gentens, ${ }^{1,2}$ María Sol Sansiñena, ${ }^{1}$ Stef Spronck ${ }^{3}$ and \\ An Van linden ${ }^{1,4}$ \\ ${ }^{1}$ University of Leuven $\mid{ }^{2}$ University of Stockholm \\ ${ }^{3}$ University of Helsinki $\mid{ }^{4}$ University of Liège
}

In this introduction, we set out the central themes of the special issue. It concentrates on imperfect function-form mappings, and discusses several cases in which specific perspectival meanings are not fully predictable on the basis of a perspectivizing grammatical construction alone. We distinguish two kinds of form-function mismatches: (1) perspective-persistent phenomena, i.e. grammatically signaled deictic and/or cognitive perspective shifts which are not realized in interpretation, and (2) irregular perspective shifts, which involve either grammatically un(der)specified shifts or grammatically signaled shifts that are interpreted as mixing multiple sources of deictic and/or cognitive perspective ('multiple-perspective constructions'). We briefly discuss and contextualize each of the contributions, and highlight their central findings.

Keywords: perspective persistence, irregular perspective shifts, formfunction mismatch, grammatical underspecification, multiple-perspective construction

This special issue focuses on the linguistic status of perspective shifts and their relation to grammar. More specifically, it concentrates on imperfect functionform mappings, and discusses several cases in which specific perspectival meanings are not fully predictable on the basis of a perspectivizing grammatical construction alone. Before we turn to the central cases of imperfect perspectiveto-construction mappings, we will first elaborate on what we regard as regular perspectivizing constructions in the following paragraphs. Such constructions are held to show the following two features: (i) 'expressions of perspective' inherently refer to some conceptualizer that needs to be pragmatically recovered in the 
speech situation and (ii) their perspectival meanings can be encoded by means of dedicated grammatical and lexical constructions. These two elements - the reference point(s) for the interpretation of expressions of perspective, and the grammatical encoding thereof - form our main concern here. The papers in this special issue explore a range of special contexts in which there is a (partial) mismatch between the referential entity signaled as the conceptualizer by a construction and the referential entity that gets interpreted to be the conceptualizer in the discourse context.

'Indexicals', i.e. expressions of perspective, whose meaning inherently involves reference to aspects of, and conceptualizers evoked in, the context of speech are essential elements of language (cf. Silverstein 1976). They include basic expressions invoking social relations between speech participants (e.g. formal (vous) versus informal $(t u)$ pronominal address terms in French), epistemic commitment on the part of the speech act participants (e.g. the speaker as source of the modal stance in He might be wrong), or temporal relations relative to the time of utterance (e.g. the interpretation of the past as located relative to now in I washed the car yesterday). All deictic expressions fall within this broad class of indexicals (Nunberg 1993; Levinson 2006; see Munro et al. 2012, 43).

Language use characteristically allows for continuous shifting of the reference point for the interpretation of perspective indexes. The linguistic encoding of such perspectival meanings in specific grammatical and lexical constructions has been a central question in studies on (inter)subjectivity (e.g. Vandelanotte 2004a; 2009; Verhagen 2005; De Smet and Verstraete 2006; Ghesquière et al. 2014; Cornillie and De Cock 2015; San Roque and Bergqvist 2015; Dancygier et al. 2016; Hinterwimmer and Schumacher 2017; San Roque et al. 2017). Prior research has shown how perspective shifts are brought about, either on the basis of the structure of dyadic interaction (e.g. turn-taking), or by means of dedicated grammatical 'shifting' constructions. As an illustration of the latter, compare the direct speech construction in (1a) to the indirect speech construction in (1b).

(1) a. John said "I will be late."

b. John said he would be late.

The construction in (1a) illustrates a regular perspective shift: while in the reporting clause (John said) the reference point for the interpretation of indexicals (i.e. deictic centre) is the current speaker, in the reported clause (I will be late) it is the reported speaker, John (cf. Halliday 1994, Ch. 5; Langacker 1987,123; Vandelanotte 2004b, 490-492). This shift in deictic perspective is regular because it is signaled by the construction (e.g. third person vs. first person; past vs. future tense; punctuation in writing and prosodic cues in speech) as well as realized in interpretation. By contrast, the indirect speech construction in ( $1 \mathrm{~b})$ does not dis- 
play such a 'deictic shift' (von Roncador 1980; 1988); all indexicals are tied to the current speaker's deictic centre, with third person pronoun he in the reported clause (he would be late) referring back to John, who remains a third person to the current speaker (Vandelanotte 2004b, 492). ${ }^{1}$

Continued interest in such grammatical shifting constructions has highlighted the complexity of the perspective structure evoked in them, which has fostered new avenues for debate (e.g. Verhagen 2005; Evans 2006; Vandelanotte 2009; Dancygier et al. 2016; Evans et al. 2018): perspective-indexing constructions do not always neatly shift from one conceptualizer's viewpoint to another's in succession; instead, multiple perspectives can be operational within the same construction. An essential preliminary step in analyzing how multiple perspectives can be integrated within the same grammatical construction (e.g. in reported speech constructions like (1a-b)), is to distinguish terminologically and conceptually between different types of perspectives or reference points. In this respect, we follow Vandelanotte (this issue) in taking as a central distinction that between 'cognitive' and 'deictic' perspective ('whose content?' vs. 'which deictic centre?'), the sources of which can show shifting or persistence. The analysis of cognitive perspective investigates to which mental consciousness the content of an utterance can be ascribed. This mental consciousness, or conceptualizer, is also the source of expressive or epistemic stances contained in the utterance (e.g. wow! you must be out of your mind!), and of the coding choices as to person reference (e.g. the choice of a pronoun 'you/she' vs. a proper name 'Mrs. Plum' to refer to the addressee in a speech event). An analysis of deictic perspective, then, examines to which deictic centre a range of phenomena relate (e.g. absolute tense, indexical person reference as in $I$ and you, and spatial/temporal adverbials such as here and now; cf. Vandelanotte 2009 , Ch. 5-7). In (1a) above, there is a cognitive shift in that the content of the utterance 'I will be late' stems from John, and this is reflected in a deictic shift towards the time and setting of John's utterance as well. In (1b), there is still a cognitive shift in representing the content of John's utterance, but no deictic shift. Within one construction, the source(s) of cognitive perspective can thus differ from the source(s) of deictic perspective, thereby allowing for the simultaneous reference to multiple perspective sources within the same construction (cf. Evans 2006).

1. As noted by Vandelanotte (2004b, 492), other authors (e.g. Vanparys 1996, 108-109; Steever 2002,98) have stated the opposite (but to the same effect), i.e. that indirect speech constructions involve a deictic shift (that is, with respect to the reported speaker's original utterance), while direct speech constructions do not (as these retain the deictic elements used in the original utterance). 
An example of a linguistic construction that has often been discussed in the context of multiple-perspective expressions, allowing for multiple reference points, is the category of free indirect speech as defined by Banfield (1982). For example, in the expression of free indirect speech in $(2)^{2}$ a represented character's thoughts or wordings mix with the perspective of the narrator. ${ }^{3}$

(2) Hilda drove in silence for some time after this piece of unheard-of insolence from that chit Connie.

\section{(Banfield 1982,186, citing Lawrence, Lady Chatterley's Lover)}

In (2), the deictic perspective is that of the narrator throughout, while there is a mix of the cognitive perspective of the narrator, i.e. the current speaker, and that of the character, i.e. the reported speaker: the qualification of Connie as a 'chit' has to be attributed to the perspective of Hilda, but in referring to Hilda with a proper name, the narrator makes his presence felt. The interpretation of perspective in free indirect speech will be dealt with in more detail in the contributions by Vandelanotte, van Duijn and Verhagen, and Zeman.

With this special issue, we aim to contribute to this emerging paradigm of research on the relation of complex perspectival meanings to grammar. More specifically, we focus on two broad types of cases in which traditional perspectiveindexing (e.g. tense, modality) or perspective-shifting (e.g. reported speech) constructions are extended beyond their basic indexical usage, and thus show imperfect perspective-to-construction mappings. On the one hand, there are grammatical constructions in which, either through language change or within the dynamics of discourse, perspective does not shift in spite of the presence of a conventional perspective-shifting marker; we call these cases of perspective persistence. ${ }^{4}$ On the other hand, there are cases were the perspective does show a certain

2. As discussed in Vandelanotte $(2004 \mathrm{~b}, 497)$, a free indirect speech construction corresponding to (1a) would be He would be late, John said (Reinhart 1975, 136).

3. As Vandelanotte (2009) remarks, free indirect speech has a multitude of definitions in the literature, not all of which automatically imply complex perspective. For example, in its most simple form, the term is often used to refer to grammatically unmarked reported speech (see $\mathrm{Si}$ and Spronck this issue), which does not always imply mixed perspective.

4. Munro et al. $(2012,44)$ coined the term 'perspective persistence' to refer to the constraint observed in the Panoan language Matses - on "maintaining the personal, temporal, and spatial point of view of the source of some information" in constructions of reported speech. While this constraint makes Matses reported speech constructions resemble direct speech reports, the authors also observed a number of phenomena in these constructions that are typical of indirect speech, such as the acceptability of substantial paraphrasing (giving up verbatim quotation). In our use of the term, cases showing perspective persistence contain elements that signal a shift in perspective (like in Matses), but - crucially - this shift in perspective is not 
shift, even if elements in the construction would suggest no or a different shift; we call these complex or irregular perspective shifts.

Constructions displaying perspective persistence are constructions which formally signal a shift in perspective, but the interpretation of the referential conceptualizer remains unaffected (i.e. the shift in perspective is not realized in interpretation). Examples include non-quotational reported speech constructions, in which the reported speech construction would suggest a perspective shift away from the current speaker, but no interpretative shift in perspective is invoked (Pascual 2014, Ch. 4; see also Vandelanotte this issue; Sandler and Pascual this issue). An example of a non-quotational, perspective-persistent, reporting construction is represented in (3).

(3) French marigolds can mean the sender is jealous. African marigolds are hardly a better pick; they indicate vulgar-mindedness. Mandevilla is trouble, too.

These flowers say "reckless" or "thoughtless."

The italicized sentence in (3) is formally a direct speech construction, and would therefore be expected to signal a deictic and cognitive shift away from the perspective of the current speaker. However, since flowers do not naturally have acts of speaking attributed to them, the construction has to be interpreted from the deictic and cognitive perspective of the current speaker. Therefore, the indexed perspective remains that of the speaker, an instance of perspective persistence. Similar uses of reported speech constructions to express speaker-based evaluations rather than actual speech reports are discussed by Vandelanotte (this issue).

Such cases of perspective persistence which are reinterpreted from both the deictic and cognitive perspective of the current speaker - rather than the grammatically indexed reported speaker - are nonetheless very rare. More common cases of perspective persistence involve only deictic persistence, like the nonquotational reported speech constructions discussed in Sandler and Pascual (this issue): while the grammatical construction signals a cognitive and deictic shift to the reported speaker's content and speech context, only the cognitive shift is realized in interpretation; there is no interpretive deictic shift to an original utterance setting. Recently, Konnerth (2016; Subm.) has described the reported intentionality construction of Monsang (Trans-Himalayan, Sino-Tibetan) as another case of (deictic) perspective persistence. An example is given in (4). Similar constructions have been found in Australia (McGregor 1994; Rumsey 2001; McGregor

realized in interpretation (which it is in Matses, but the current speaker may have manipulated the original utterance).

5. https://pilotonline.com/life/home/lawn-garden/flower-speak-what-your-flowers-really-say /article_bba7ee7o-bfbe-559c-a904-169313eofb48.html 
2007; Spronck 2015), Africa (Güldemann 2008), and South America (Adelaar 1990; Everett 2008).

\section{(4) [ámátfìn [átè tò-gé-tè] $\quad$ té-d $\left.3^{9}-n g ́\right]$} and.then now cut:I-1SG-COHORT.FUT say-ADD-FUT:3 'and even if people want to cut (it)...' (lit., 'even if people say, "let me cut (it)"') (two trees 046)

(Konnerth 2016; Subm)

The expression in (4) has the idiomatic translation '(even if) people want to cut (it)', which derives from a reported speech construction that can be translated as '(even if) people say "let me cut (it)"' (Konnerth 2016; Subm). The construction requires the verb in the reported clause (within inner brackets) to index a first person argument that is coreferential with the volitional agent, indexed as the third person subject of the reporting clause (within outer brackets). While the construction signals a cognitive and deictic shift in perspective from the current speaker to the volitional agent, the deictic shift is not realized in interpretation. Inasmuch as the idiomatic meaning of the construction adopts the deictic perspective of the current speaker only, the construction displays a mismatch between its biperspectival form and its uniperspectival meaning (Konnerth 2016; Subm). This and additional examples of perspective persistence (as well as irregular perspective shifts) from lesser described languages will be discussed in a thematically related special issue with the same guest-editorial team (Spronck et al. Subm.).

Complex or irregular perspective shifts involve shifts in perspective which either have an indexed source deviating from the one that is expected on the basis of the grammatical construction, or which complicate the perspective structure by adding an additional perspective that is not inherent to the construction. Examples of irregular perspective shifts include instances of reported speech constructions in which the matrix clause remains unexpressed, where the irregularity lies in the fact that a shift occurs, despite the absence of a conventional marker for this shift (see Spronck 2017; Si and Spronck this issue). If the discourse context is such that multiple perspectivizing sources are available, e.g. in a narrative with multiple layers of narrators, this can lead to (intended) ambiguities as to which perspectival source can be inferred (see van Duijn and Verhagen this issue).

Another example of an irregular perspective shift is illustrated by (5). The example involves a reported clause which conventionally shifts the perspective to that of the represented speaker, Desailly. On top of that shift, however, the use of the lexical reporting verb claim indexes an additional perspective on the part of the actual speaker/writer which is not inherent to the reporting construction. It indicates that the propositional content of the report which is attributed to the reported speaker is evaluated as unlikely by the current speaker. 
(5) The injury has hampered Desailly throughout this season. He even claimed it was his Achilles which gave him toothache, forcing him to miss last month's trip to Tel Aviv.

(Wordbanks Online Corpus)

A more complex example of an irregular shift is found in echoic modality, by means of which a speaker echoes "some position voiced or implied in the preceding discourse" (Verstraete 2007, 216). Modal auxiliaries typically have the speaker as the source in declaratives, and conventionally shift the source of the modality to the represented speaker in reporting constructions. Example (6), which contains a modal within what is formally a reported clause, represents a different scenario: in each of the two reporting constructions, the commitment to the modal position of desirability is not shifted to the represented conceptualizer of the reporting clause, nor does the commitment remain with that of the speaker. Instead, the echoic modal displaces the commitment to the modal stance to a third perspectival source, i.e. to a contextually available source of information ('many people') other than the represented speaker.

(6) Over the years, many people have written both positively and negatively about the NCFIC. Here are the seven most common mischaracterizations. (...) The NCFIC believes that the whole family must always be together for all gatherings.

False. We have never said that the whole family must be together for all gatherings.

(Wordbanks Online Corpus, cited in Gentens 2016,106, ex. (44); see also Gentens and Davidse 2017,86, 90-92)

Similar types of irregular perspective shifts are found in many multipleperspective constructions (Evans 2006; Spronck 2012; San Roque and Bergqvist 2015; see also Vandelanotte this issue; van Duijn and Verhagen this issue; Zeman this issue).

The unique focus on perspective persistence and irregular perspective shifts sets apart this issue from the vast amount of prior research on the expression of perspective. Its aim is to present a first publication dedicated solely to the range of functional extensions that may lead to, or originate from, (conventional) perspective-shift markers, or from the absence of perspective indexing markers (Spronck 2017; Si and Spronck this issue).

Besides offering terminological clarifications, the various contributions to the issue zoom in on the descriptive status of diverse local phenomena at the levels of the noun phrase (pronoun and/or proper name reference), the verb phrase (modal future in the past, negation, temporal adverbs) and the clause (co-presence of non-quotative reportative markers). The key to understanding the persistent or shifted perspective indexed by these local phenomena lies in 
their relation to a larger perspective structure with a specific discourse set-up or genre convention (e.g. knowledge of internet meme conventions, narrative genres which allow for a subjective view on the part of the writer or protagonist, see this issue's papers by Vandelanotte, van Duijn and Verhagen, Zeman). Given such genre conventions, the construction may also appear in a reduced form, keeping only some of its central features, as discussed in the contributions dealing with un(der)marked perspective shifts (this issue's papers by Vandelanotte, van Duijn and Verhagen, Sandler and Pascual, Si and Spronck). We will now briefly introduce the main empirical phenomena, and their relation to perspective shifts or persistence, as they are discussed in the individual papers in this issue.

Vandelanotte discusses the phenomena of irregular perspective shift and perspective persistence with respect to reported speech (including reported thought) constructions. If we consider direct speech as a central conventionalized construction type to encode a full cognitive, (i.e. mental and evaluative content-related) and deictic (i.e. temporal, spatial, and speech-situation-related) shift from the current speaker or narrator to a represented speaker or character (cf. ex (1a)), other subtypes of reporting constructions, such as free indirect speech (cf. ex (2) and fn. 2), show irregular shifts: the deictic and cognitive perspectives encoded in them mix features related to the represented speaker and to the current speaker/narrator, thus inherently evoking multiple perspective sources within the reported utterance. The author discusses the value of a range of lower-level perspective markers within reported speech, such as person reference accessibility coding (pronoun vs. full NP), expressivity, basic clause types, and deictic centre for tense, person, and spatio-temporal marking. He shows how the relative import of these local phenomena and the combinations of cognitive and deictic perspectives they construe crystallize into four distinct subtypes of reported speech constructions, which cover a whole spectrum ranging from full-blown shifting constructions (direct speech) to multiple-perspective constructions prioritizing the actual speaker's perspective (distancing indirect speech).

In a second case-study, Vandelanotte turns to instances where the grammar of reporting constructions is used as a full-blown perspective-persistent index for the expression of speaker comments. He focuses on non-quotative reporting constructions of the type "I love your crocs", said no one ever in internet memes. These memes evoke a reported speech frame and thereby suggest an apparent deictic and cognitive shift towards the perspective of some reported speaker. However, when interpreting these memes, the perspective shifts suggested by the reporting frame are explicitly cancelled, for the purpose of expressing (negative) speaker evaluations such as ridicule or vehement disapproval. These uses of reported speech are perspective-persistent, in that they do not involve an actual shift towards another conceptualizer's cognitive and deictic perspective despite 
the direct speech reporting frame, and instead are used to express implicit current speaker-related evaluations.

Van Duijn and Verhagen discuss three cases which can be considered as multiple-perspective structures, in which several perspectivizing sources are simultaneously relevant and difficult to tease apart within the same narrative or grammatical structure. On the theoretical plane, they propose a conceptual model for the linguistic construction of viewpoint, based on the premise that the complexity of mixed-viewpoint situations is often not well-described by the widely used models of recursive embedding and perspective shifts. The authors illustrate the importance of recognizing the complexity and potential for grammatical underspecification of multiple-perspective structures, and argue for the suitability of their communication model for analysing them. They focus on three case studies in three different languages: one at a narrative level (English) and two at the level of specific grammatical constructions (Dutch, Russian).

The first case study zooms in on grammatically un(der)marked perspective shifts, and the processes that guide our interpretation of the perspectivizing cues we find in them. The focus is on the tension between the global and local perspective structures in the novel Lolita, by Vladimir Nabokov, by means of which they emphasize the relation of grammatically underspecified (and in that sense, irregular) shifts to the analysis of the particular genre and perspective structure of the entire text (see also Zeman this issue; Vandelanotte, this issue). The conceptual model of interaction proposed by the authors allows them to analytically represent the multiple-perspective narrative, with its ambiguities, in a thoughtscape or network of coexisting, multiple sources for cognitive and deictic viewpoints.

The second study turns to grammatical constructions of direct speech in Dutch, and focuses on contrasts between those with a preposed reporting matrix (X said: ...) vs. those with a postposed reporting matrix (..., said $X$ ), which are traditionally subsumed under the direct speech construction as two variants. Parallel to the first goal of Vandelanotte (this issue), van Duijn and Verhagen propose that these two construction patterns in fact constitute two distinct construction types, because they occupy different positions on the scale from full-blown shifting direct speech constructions over multiple-perspective constructions to perspectivepersistent uses of reporting constructions (see the summary of Vandelanotte this issue). It is argued that while the 'citation construction' - with a preposed reporting clause - is a conventional shifting construction, the 'inquit construction' - with a postposed reporting clause - is in fact a multiple-perspective construction.

The third study, finally, deals with the Russian 'apprehensive construction' kak by ... ne $X$, in which the presence of the negation marker ne seems to be redundant. Constructions consisting of a clause with a predicate of fearing combined with a clause introduced by kak by are traditionally analyzed as a conventional 
shifting construction, with the second clause functionally representing the content of the fear described in the first clause, and formally seen as a subordinate complement clause to the predicate of fearing. The negation marker in the second clause, however, is not a part of the propositional content of what is feared, which creates a form-function mismatch. The authors build on the non-truthconditional meaning of the negation marker and on the frequency of the kak by ... ne-clause without an accompanying clause of fearing to argue for an alternative analysis of such clause combinations as involving parataxis rather than subordination. This analysis suggests that despite the apparent grammatical resemblance of the clause combinations to conventional shifting constructions involving complementation, they in fact involve two independent clauses (an expression of the projection that an unfortunate situation is likely to occur, followed by a wish that that situation will not be realized).

Zeman presents an analysis of future-of-fate constructions, as in He was never to return, with a main focus on this use in German (sollte + infinitive) and Homeric Greek (émelle + infinitive) as originating in verbs with deontic meanings of obligation and intention. Future-of-fate constructions are multiple-perspective constructions, which encode diverging knowledge stores: a sentence such as $\mathrm{He}$ was never to return involves (i) a narrator's certainty that an event of returning will not take place in the later course of the story line, (ii) while the character referred to as he does not have such knowledge about future events.

If we look at the way these different perspectives are encoded grammatically, we see that future-of-fate constructions count as instances of irregular perspective shift. As Zeman shows, in a range of European languages future-of-fate interpretations tend to derive from modal verbs expressing deontic necessity/obligation. Such verbs are traditionally associated with perspective-taking: if a speaker utters a sentence such as You are to/must return, we can expect the assessment of modal necessity encoded in are to to relate to the speaker uttering the sentence. However, they are not traditionally associated with the encoding of the complex perspectival meaning studied here, which involves one conceptualizer's certainty (the narrator's) as opposed to another conceptualizer's ignorance (the character). This clash between the conventionalized marking of certain perspectival meanings in dedicated grammatical markers on the one hand and the complex perspectival meanings that go above and beyond the grammatical context on the other represents what we defined as an 'irregular perspective shift'.

Zeman provides a detailed analysis of the grammatical-semantic and contextdependent ingredients required to allow for a future-of-fate interpretation. In terms of grammatical semantics, all future-of-fate interpretations are associated with modal verbs of past obligation. In terms of discourse context, the complex perspectival meaning only arises in narrative modes that allow for the narrator to 
intervene. On the basis of these components, future-of-fate constructions therefore evoke three different temporal reference points that can be correlated with perspective-taking: (i) the past obligation encoded in the modal verb, (ii) the time of the event to be realized, encoded in the infinitive, and (iii) the here-and-now of the narrator, with respect to which both (i) and (ii) are in the past. In this way the author explicitly addresses the central question of which ingredients for complex perspectival meanings are derived from the grammatical construction, and which are supplied from the narrative context.

In a similar vein as Vandelanotte (this issue) and van Duijn and Verhagen (this issue), the contribution by Sandler and Pascual takes a closer look at specific grammatical constructions of direct speech to tease apart their various functions with respect to perspective shifting, in this case focusing on the Hebrew Bible as a data source. The authors show that, in Biblical Hebrew as well as crosslinguistically, the grammar of direct speech constructions is used not only to describe people's actual utterances, thus serving its familiar quotative function, but also to express a range of other meanings. These other meanings share with reported utterances the feature that they involve a cognitive shift towards the perspective of a conceptualizer invoked in the main clause, but differ from them in that they may carry other meanings associated with clause combining structures beyond the domain of complementation (Verstraete 2008). They span the range from more traditional complementation-related meanings such as reported thought and volition to more adverbial-like meanings, for example related to the reason for, the result of, the import of, or the realization of an event. These phenomena are cases of deictic perspective persistence, since the use of direct speech grammatically encodes a cognitive and deictic shift towards the character's perspective, but the deictic shift towards an original utterance setting is not realized in interpretation. On a theoretical level, the prevalence of fictive speech to cover a range of perspectivizing functions in the Hebrew Bible bolsters the authors' analysis of the conversational frame (i.e. turn-taking from one conversational participant to another as implied in direct speech sequences) as a basic conceptual model for expressing perspective shifts across languages.

Si and Spronck deal with reported speech constructions in Solega, an underdescribed Dravidian language spoken in the south of India. On the one hand, the paper gives a descriptive account of the range of reporting structures in Solega, and the range of indexical elements attested in them. On the other hand, the authors advocate a definition of reported speech that does not depend on the presence of grammatical marking. Instead, they start from a three-fold semantic definition of reporting constructions, as necessarily involving (i) the semiotic status of the report as a metarepresentation, i.e. as an utterance, (ii) the modal effect of commitment suspension on the part of the current speaker, who is merely 
reporting someone else's assertions or doubts, and (iii) the evidential status of the report as originating in an event distinct from the here-and-now of the current speaker. Having laid out these semantic ingredients, the authors correlate these three components with a range of optional grammatical reflexes, which are often left grammatically underspecified in Solega. The predominance of grammatical underspecification of perspective shift leads them to focus more narrowly on cases where there is a cognitive perspective shift without any apparent constructional cue that signals it (even if speakers have such cues at their disposal). The paper thus probes a central question in this issue, namely what should be the basis of defining conventionalized perspective shift 'constructions' and more specifically looks at how the grammatical underspecification of such shifts could be regarded as instantiating irregular perspective shifts.

Taken together, the detailed empirical analyses presented in this issue provide the basis for a wider theoretical framework on perspective-indexing constructions. They demonstrate the pervasiveness of perspective shifts in communicative and social interaction, and show how this makes expressions of perspective all the more apt for extensions beyond their basic perspective-shifting uses (see also Verschueren's epilogue to this issue). The focus lies on perspective-persistent phenomena, i.e. grammatically signaled deictic and/or cognitive perspective shifts which are not realized in interpretation, and on irregular perspective shifts, which involve either grammatically un(der)specified shifts or grammatically signaled shifts that are interpreted as mixing multiple sources of deictic and/or cognitive perspective ('multiple-perspective constructions'). By examining conventional perspective-indexes (e.g. markers of modal obligation, evaluative expressions) and perspective shifters (e.g. direct speech constructions) from this angle, we hope to shed new light on the subtlety, variety, and complexity underlying the linguistic encoding and interpretation of perspective.

\section{References}

Adelaar, Willem F. H. 1990. "The Role of Quotations in Andean Discourse." In Unity in Diversity: Papers Presented to Simon C. Dik on His 5oth Birthday, ed. by Harm Pinkster, and Inge Genee, 1-12. Dordrecht and Providence, RI: Foris publications. https://doi.org/10.1515/9783110847420.1

Banfield, Ann. 1982. Unspeakable Sentences: Narration and Representation in the Language of Fiction. Boston, MA: Routledge and Kegan Paul.

Cornillie, Bert, and Barbara De Cock (eds). 2015. Hearer-Orientation in Spoken Genres. Amsterdam: John Benjamins.

De Smet, Hendrik, and Jean-Christophe Verstraete. 2006. "Coming to Terms with Subjectivity." Cognitive Linguistics 17: 365-392. 
Dancygier, Barbara, Wei-Lun Lu, and Arie Verhagen. 2016. Viewpoint and the Fabric of Meaning. Form and Use of Viewpoint Tools across Languages and Modalities. Berlin: Mouton. https://doi.org/10.1515/9783110365467

Evans, Nick. 2006. "View with a View: Towards a Typology of Multiple Perspective Constructions." In Proceedings of the Thirty-first Annual Meeting of the Berkeley Linguistics Society, ed. by Rebecca T. Cover, and Yuni Kim, 93-120. Berkeley, CA: Berkeley Linguistics Society.

Evans, Nick, Henrik Bergqvist, and Lila San Roque. 2018. “The Grammar of Engagement I: Framework and Initial Exemplification." Language and Cognition 10 (1): 110-140. https://doi.org/10.1017/langcog.2017.21

Everett, Daniel. 2008. "Wari' Intentional State Constructions.” In Investigations of the SyntaxSemantics-Pragmatics Interface, ed. by Robert D. van Valin, 381-409. Amsterdam: John Benjamins. https://doi.org/10.1075/slcs.105.27eve

Gentens, Caroline. 2016. "The Factive-Reported Distinction in English. Representational and Interpersonal Semantics." Ph.D. dissertation, University of Leuven.

Gentens, Caroline, and Kristin Davidse. 2017. "Reconceptualizing Factivity: a New View on the Semantics of Factive Constructions." Leuven Working Papers in Linguistics 35 (6): 65-95.

Ghesquière, Lobke, Lot Brems, and Freek van de Velde (eds). 2014. Intersubjectivity and Intersubjectification in Grammar and Discourse. Amsterdam: John Benjamins.

Güldemann, Tom. 2008. Quotative Indexes in African Languages: A Synchronic and Diachronic Survey. Berlin: de Gruyter Mouton. https://doi.org/10.1515/9783110211450

Halliday, Michael A. K. 1994. An Introduction to Functional Grammar, 2nd ed. London: Arnold. Hinterwimmer, Stefan, and Petra B. Schumacher (eds). 2017. Special Issue on Perspective Taking. Glossa (2) 1 .

Konnerth, Linda. 2016. "Speech-act Participant Perspectives in Quotative Constructions of Monsang." Paper presented at SLE49, University of Naples, 31 August - 3 September 2016.

Konnerth, Linda. Subm. "Recycling through Perspective Persistence in Monsang (TransHimalayan): Reconstructing the Desiderative from a Reported Intentionality Construction." Functions of Language.

Langacker, Ronald W. 1987. Foundations of Cognitive Grammar. Volume I: Theoretical Prerequisites. Stanford, CA: Stanford University Press.

Levinson, Stephen. 2006. “Deixis.” In The Handbook of Pragmatics, ed. by Laurence R. Horn and Gregory L. Ward, 97-120. Malden, MA: Blackwell.

https://doi.org/10.1002/9780470756959.ch5

McGregor, William B. 1994. "The Grammar of Reported Speech and Thought in Gooniyandi." Australian Journal of Linguistics 14 (1): 63-92. https://doi.org/10.1080/07268609408599502

McGregor, William B. 2007. “A Desiderative Complement Construction in Warrwa.” In Language Description, History and Development: Linguistic Indulgence in Memory of Terry Crowley, ed. by Jeff Siegel, John Lynch, and Diana Eades, 27-40. Amsterdam: John Benjamins. https://doi.org/10.1075/cll.30.08mcg

Munro, Robert, Rainer Ludwig, Uli Sauerland, and David W. Fleck. 2012. "Reported Speech in Matses: Perspective Persistence and Evidential Narratives." International Journal of American Linguistics 78 (1): 41-75. https://doi.org/10.1086/662637

Nunberg, Geoffrey. 1993. “Indexicality and Deixis." Linguistics and Philosophy 16:1-43. https://doi.org/10.1007/BFoo984721

Pascual, Esther. 2014. Fictive Interaction: The Conversation Frame in Thought, Language, and Discourse. Amsterdam: John Benjamins. https://doi.org/10.1075/hcp.47 
Reinhart, Tanya. 1975. "Whose Main Clause? Point of View in Sentences with Parentheticals." In Harvard Studies of Syntax and Semantics: Vol. 1, ed. by Susumu Kuno, 127-171. Cambridge, MA: Dept. of Linguistics, Harvard University.

Rumsey, Alan. 2001. "On the Syntax and Semantics of Trying." In Forty Years on: Ken Hale and Australian Languages, ed. by Jane Simpson, David Nash, Mary Laughren, Peter Austin, and Barry Alpher, 353-63. Canberra: Pacific Linguistics.

San Roque, Lila, and Henrik Bergqvist (eds). 2015. Special Issue on Epistemic Marking in Typological Perspective. STUF - Language Typology and Universals.

San Roque, Lila, Floyd, Simeon, and Elisabeth Norcliffe. 2017. "Evidentiality and Interrogativity.” Lingua 186-187: 120-143. https://doi.org/10.1016/j.lingua.2014.11.003

Silverstein, Michael. 1976. "Shifters, Linguistic Categories, and Cultural Description.” In Meaning in Anthropology, ed. by Keith H. Basso, and Henry A. Selby, 11-55. Albuquerque: University of New Mexico Press.

Spronck, Stef. 2012. "Minds Divided, Speaker Attitudes in Quotatives." In Quotatives: CrossLinguistic and Cross-Disciplinary Perspectives, ed. by Isabelle Buchstaller, and Ingrid van Alphen, 71-116. Amsterdam: John Benjamins.

https://doi.org/10.1075/celcr.15.07spr

Spronck, Stef. 2015. "Reported Speech in Ungarinyin: Grammar and Social Cognition in a Language of the Kimberley Region, Western Australia." Ph.D. dissertation, Canberra: Australian National University.

Spronck, Stef. 2017. "Defenestration: Deconstructing the Frame-in Relation in Ungarinyin." Journal of Pragmatics 114: 104-133. https://doi.org/10.1016/j.pragma.2017.03.016

Spronck, Stef, An Van linden, Caroline Gentens, and Maria S. Sansiñena (eds.). Subm. Notes from the Field on Perspective-Indexing Constructions: Irregular Shifts and Perspective Persistence. Functions of Language.

Steever, Sanford B. 2002. "Direct and Indirect Discourse in Tamil." In Reported Discourse: A Meeting Ground for Different Linguistic Domains, ed. by Tom Güldemann, and Manfred von Roncador, 91-108. Amsterdam: John Benjamins. https://doi.org/10.1075/tsl.52.07ste

Vandelanotte, Lieven. 2004a. "From Representational to Scopal Distancing Indirect Speech or Thought: A Cline of Subjectification." Text 24 (4): 547-585. https://doi.org/10.1515/text.2004.24.4.547

Vandelanotte, Lieven. 2004b. "Deixis and Grounding in Speech and Thought Representation." Journal of Pragmatics 36: 489-520. https://doi.org/10.1016/j.pragma.2003.10.003

Vandelanotte, Lieven. 2009. Speech and Thought Representation in English. A CognitiveFunctional Perspective. Berlin: Mouton. https://doi.org/10.1515/9783110215373

Vanparys, Johan. 1996. Categories and Complements of Illocutionary Verbs in a Cognitive Perspective. Frankfurt am Main: Peter Lang.

Verhagen, Arie. 2005. Constructions of Intersubjectivity: Discourse, Syntax, and Cognition. Oxford: Oxford University Press.

Verstraete, Jean-Christophe. 2007. Rethinking the Coordinate-Subordinate Dichotomy. Interpersonal Grammar and the Analysis of Adverbial Clauses in English. Berlin: Mouton. https://doi.org/10.1515/9783110918199

Verstraete, Jean-Christophe. 2008. "The Status of Purpose, Reason and Intended Endpoint in the Typology of Complex Sentences: Implications for Layered Models of Clause Structure." Linguistics 46: 757-788. https://doi.org/10.1515/LING.2008.025 
von Roncador, Manfred. 1980. “Gibt die Redewiedergabe Rede wieder?” L.A.U.T. (Linguistic Agency University of Trier), Series A: Paper no. 71.

von Roncador, Manfred. 1988. Zwischen direkter und indirekter Rede: Nichtwörtliche direkte

Rede, erlebte Rede, logophorische Konstruktionen und Verwandtes. Tübingen: Niemeyer. https://doi.org/10.1515/9783111678764

\title{
Address for correspondence
}

\author{
Caroline Gentens \\ Department of English \\ Universitetsvägen $10 \mathrm{E}$ \\ Stockholm University \\ S-106 91 Stockholm
}

Sweden

caroline.gentens@english.su.se

caroline.gentens@kuleuven.be

\section{Biographical notes}

Caroline Gentens is a postdoctoral researcher at the University of Stockholm, and affiliated researcher at the University of Leuven. She obtained her $\mathrm{PhD}$ from the University of Leuven in December 2016. Her main research interests are complementation and clause combining, factivity, event structure, modality, and the functional structure of the NP.

María Sol Sansiñena is assistant professor of Spanish linguistics at the University of Leuven and adjunct researcher at the University of Antwerp. She has also worked at the National University of Córdoba, at Ghent University and at the University of Liège. Her research interests include interaction and grammar, pragmatics, complementation and clause combining, the analysis of mood and modality, grammaticalization and constructionalization, and language variation.

Stef Spronck (PhD The Australian National University 2016) is a postdoctoral researcher at the University of Helsinki, and previously at the University of Leuven. After his training in Slavic and General linguistics at the University of Amsterdam he carried out extensive documentary fieldwork in Aboriginal Australia, working on reported speech and stance in Ungarinyin. His research focuses on typology, dialogic linguistics and reported speech/TAME.

An Van linden is assistant professor of English language and linguistics at the University of Liège and affiliated researcher at the University of Leuven. Her research interests include the analysis of clause combining, mood and modality, information structure and grammaticalization in the NP, from a diachronic and a synchronic perspective, in the Germanic languages as well as in typologically diverse languages. She is also describing Harakmbut, an unclassified language from the Peruvian Amazon. 